\title{
Crystallization and preliminary $X$-ray diffraction studies of the oxygenating subunit of 3,6-diketocamphane monooxygenase from Pseudomonas putida
}

\author{
Emma J. McGhie, Michail N. Islpov, Ewald Schröder and Jennifle A. LitTlechild* at Departments of Chemistry and \\ Biological Sciences, University of Exeter, Exeter EX4 4QD, England. E-mail: jalittle@ex.ac.uk
}

(Received 9 December 1997; accepted I April 1998)

\begin{abstract}
The oxygenating constituent of the 3.6-diketocamphane monooxygenase isozyme from Pseudomonas putida NCIMB 10007 has been crystallized under two different conditions. Crystals were initially grown from polyethylene glycol (PEG) 8000 and sodium acetate using the vapour-phase diffusion method. The crystals were of orthorhombic $P 2_{1} 2_{1} 2_{1}$ space group, with cell dimensions $a=55.8, b=94.5$ and $c=163.7 \AA$ and diffracted to $2.8 \AA$ resolution. More recently, improved crystals, which diffracted beyond $2 \AA$, have been grown from ammonium sulfate. These crystals also belong to the orthorhombic $P 22_{1} 2_{1} 2_{1}$ space group, with cell dimensions of $a=54.6 . b=93.2$ and $c=154.1 \mathrm{~A}$. A full native data set to $2.5 \AA$ resolution has been collected from the ammonium sulfate grown crystals.
\end{abstract}

\section{Introduction}

It is known that Pseudomonas putida NCIMB 10007 is able to grow on either cnantiomer of camphor as the sole carbon source (LeGall et al., 1963). Whereas the metabolism of (+)-camphor has been widely researched and reviewed (Conrad et al., 1965; Gunsalus \& Marshall, 1971; Taylor \& Trudgill, 1986), there have been comparatively few studies of the fate of the complementary optical antipode (Williams, 1991: Jones et al. 1993). It has been established that various monooxygenases play key roles in the dissimilation of both camphor enantiomers.

Both (+)- and (-)-camphor are initially hydroxylated by a shared cytochrome P450-dependent monooxygenase induced by growth on either enantiomer (Fig. 1). However, the subsequent oxidative steps. including the Baeyer-Villiger monooxygenase-dependent ring-cleavage reaction that results in the formation of monocyclic pathway intermediates from diketocamphane precursors are catalysed by enantiocomplementary enzymes (Fig. 1). These are induced irrespective of the camphor enantiomer used for growth (Taylor \& Trudgill. 1986; Jones et al., 1993).

Two diketocamphane monooxygenases from $P$. putida have been found to catalyse a number of oxygenative biotransformations with various natural and synthetic ketones. These reactions confirmed that each of the two isozymes possesses distinct enantioselective properties and can, in some cases, be exploited to undertake key reactions in the chemoenzymatic synthesis of commercially useful products (Gagnon et al., 1994; Grogan et al., 1992, Grogan, Roberts \& Willetts, 1993; Grogan, Roberts, Wan et al., 1993).

Previous studies have suggested that both the 2.5-diketocamphane monooxygenase (Williams, 1991; Grogan, 199.5) and the 3,6-diketocamphane monooxygenase (Jones et al., 1993; Grogan, 1995) are composed of a loose trimeric complex. Each complex consists of an NADH dehydrogenase, which may be common to both flavoproteins, and a homodimer of identical oxygenating subunits, that determine the specificity of the isozymes. The oxygenating subunits have a monomeric subunit molecular weight of 40 and $42 \mathrm{kDa}$ for the $2.5-$ and 3,6-diketocamphane monooxygenase oxygenating subunits, respectively. N-terminal sequence analysis of both types of oxygenating subunits show the enzymes to be related but clearly different proteins. Some limited sequence homology exists between the monooxygenase oxygenating subunits and luciferase from Vibrio harveyii.

No structural information on the diketocamphane monooxygenase enzymes has been reported to date. Structural and mechanistic comparisons of the diketocamphane monooxygenase isozymes and details of their active sites will enable the rational design of novel substrates as well as the modification of the substrate specificity of the enzymes by sitedirected mutagenesis. This will expand the application of one or both isozymes for useful large-scale biotransformation reactions. Here we present the crystallization of the oxygenating component of the 3.6-diketocamphane monoxygenase.

\section{Materials and methods}

Pseudomonas putida NCIMB 10007 cells (241) were grown on (士)-camphor, harvested and broken by sonication (McGhic \& Littlechild, 1996). The crude protein extract was made $50 \%(w / v)$ saturated with respect to enzyme-grade ammonium sulfate and the resulting supernatant was then taken to $75 \%$ saturation. The resulting pellet was dissolved in buffer $A$ $\left[21 \mathrm{~m} M \mathrm{KH}_{2} \mathrm{PO}_{4} / \mathrm{K}_{2} \mathrm{HPO}_{4}, \mathrm{pH}\right.$ 7.1. $6 \mathrm{~m} M \beta$-mercaptoethanol, $0.1 \mathrm{~m} M$ EDTA, $10 \mu M$ phenylmethylsulfonylfluoride (PMSF) and $20 \mu M$ benzamidine (BAM)] and dialysed overnight against the same buffer. This was then applied directly to a pre-equilibrated Fast-flow-Q anion-exchange column (Pharmacia; $6 \times 18 \mathrm{~cm}$ ) in buffer $A$. The protein was eluted with a 1.51 linear gradient of $0-0.45 M$ potassium chloride in buffer $A$.

The active fractions corresponding to the 3,6-diketocamphane monooxygenase eluted at $0.3-0.35 \mathrm{M} \mathrm{KCl}$ and were pooled and concentrated by precipitation with $80 \%(w / v)$ ammonium sulfate. The enzyme was then dissolved in a minimal amount of buffer $A$ and dialysed overnight in 51 of the same buffer. The dialysate was then directly loaded onto a preequilibrated Mono-Q anion-exchange column (Pharmacia; 0.5 $\times 5 \mathrm{~cm}$ ) in buffer $A$. The enzyme was eluted using a $50 \mathrm{ml}$ linear gradient of $0-0.45 \mathrm{M}$ potassium chloride in buffer $A$. Active fractions were again pooled and concentrated by precipitation with $80 \%(w / v)$ ammonium sulfate as above. The resulting pellet was resuspended in buffer $B(21 \mathrm{mM}$ $\mathrm{KH}_{2} \mathrm{PO}_{4} / \mathrm{K}_{2} \mathrm{HPO}_{4}, \mathrm{pH} 7.1,5 \%\left(\mathrm{NH}_{4}\right)_{2} \mathrm{SO}_{4}, 6 \mathrm{~m} M \beta$-mercap- 
toethanol, $0.1 \mathrm{~m} M$ EDTA, $1 \times 10^{-5} M$ PMSF and $2 \times 10^{-5} M$ BAM) and loaded onto a pre-equilibrated Superose 12 gelfiltration column (Pharmacia; $3.5 \times 32 \mathrm{~cm}$ ) with buffer $B$. The active fractions were again pooled.

\subsection{Activity assays}

The activity of 3,6-diketocamphane monooxygenase was assayed using a modification of the method of Jones et al. (1993). A standard $1 \mathrm{ml}$ volume was used for each assay, containing $120 \mu \mathrm{mol} \mathrm{KH}_{2} \mathrm{PO}_{4} / \mathrm{K}_{2} \mathrm{HPO}_{4}$ buffer, $\mathrm{pH} 7.1$, and $0.15 \mu \mathrm{mol} \mathrm{NADH}$. Once an appropriate amount of protein solution was added, the endogenous change in the extinction of NADH was followed for $30 \mathrm{~s}$ against a blank (buffer and $\mathrm{NADH})$ at $340 \mathrm{~nm}$. A subsequent addition of $1 \mu \mathrm{mol}$ (-)-camphor was made and the ensuing oxidation of NADH was measured for a further minute. The final activity measurement was the difference between the two recorded activities.

A gas-chromatography assay was also used to identify the activity of the 3,6-diketocamphane monooxygenase oxygenating component in later stages, as the prior purification steps<smiles>CC12CCC(CC1=O)C2(C)C</smiles>

(-)-camphor

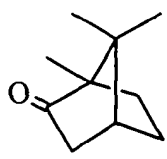

(+)-camphor<smiles>CC1(C)C2CC(C(=O)O)C(CC2=O)C1(C)C</smiles>

(1)

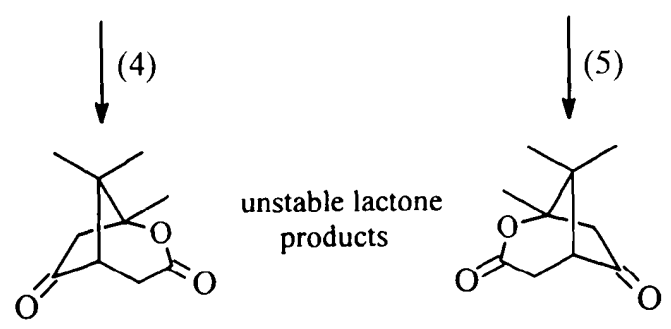

Fig. 1. The camphor degradation pathway. The following enzymes are indicated: (1), 5-exo-hydroxylase (P450 (СAM); (2) and (3), exohydroxycamphor dehydrogenases; (4), 2,5-diketocamphane monooxygenase; (5), 3,6-diketocamphane monooxygenase. resulted in the removal of the NADH dehydrogenase and so no activity of the active complex was observed using the assay described above. This method monitors the activity of the subunit to specifically lactonize the (-)-camphor substrate, which will still minimally occur in the absence of the NADH dehydrogenase. $200 \mu \mathrm{l}$ of the relevant column fraction was mixed with $5 \mathrm{nmol} F \mathrm{FN}$ and $0.2 \mu \mathrm{mol} \mathrm{NADH}$, and $0.2 \mu \mathrm{mol}$ of (-)-camphor was added. This tube was subsequently shaken at $150 \mathrm{rev} \min ^{-1}$ for $1 \mathrm{~h}$ at room temperature. Extraction was carried out by adding $200 \mu$ l of ethyl acetate, homogenizing the mixture thoroughly and subsequently centrifuging the mixture

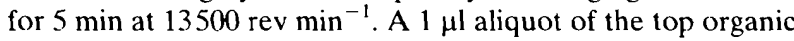
layer was then removed and analysed using a Shimadzu GC14A FID gas chromatograph equipped with a capillary column (BP1, $25 \mathrm{~m}$ ). The column was heated to $473 \mathrm{~K}$, with the detector and injector temperatures being set at 523 and $473 \mathrm{~K}$, respectively.

\subsection{Crystallization 1}

The dimeric oxygenating component was concentrated in a Centricon concentrator (Millipore). A buffer exchange was carried out by the addition of $4 \times 2.5 \mathrm{ml}$ of buffer $C(10 \mathrm{~m} M$ PIPES, pH 6.5, containing $1 \mathrm{~m} M$ DTT). After concentration to approximately $10 \mathrm{mg} \mathrm{ml}^{-1}$, the protein was crystallized by vapour diffusion using the hanging-drop technique. The hanging drops $(8 \mu \mathrm{l}$ protein, $1 \mu \mathrm{l} 40 \%$ PEG 8000 and $1 \mu \mathrm{l} 2 M$ sodium acetate) were suspended in sealed compartments above a $15 \%(w / v)$ solution of PEG 8000 containing $0.2 \mathrm{M}$ sodium acetate and incubated at $290 \mathrm{~K}$.

\subsection{Crystallization 2}

The dimeric oxygenating component was concentrated in a Centricon concentrator (Millipore). A buffer exchange was carried out by the addition of $4 \times 2.5 \mathrm{ml}$ of buffer $D(50 \mathrm{mM}$ PIPES, pH 6.5, containing $1 \mathrm{~m} M$ DTT). The crystals were again grown by the hanging-drop vapour-diffusion method. A drop containing $9 \mu \mathrm{l}$ of an $8 \mathrm{mg} \mathrm{ml}^{-1}$ protein solution and $1 \mu \mathrm{l}$ saturated ammonium sulfate was equilibrated over a rescrvoir of $50 \mathrm{~m} M$ PIPES, pH 6.5 , and $50 \%$ ammonium sulfate at $290 \mathrm{~K}$.

\subsection{X-ray data collection}

All data were collected at the Daresbury Synchrotron using MAR image plates. Data for the PEG-grown crystals were collected on beamline 7.2 using a wavelength of $1.448 \AA$. Data for the ammonium sulfate grown crystals were collected on beamline 9.5 using a wavelength of $1.000 \AA$. Diffraction was recorded at room temperature for the PEG-grown crystals and under cryogenic conditions for the ammonium sulfate grown crystals. The data were processed using the $D E N Z O$ suite of programs (Otwinowski \& Minor, 1997).

\section{Results and discussion}

It was found that a similar crystal form was grown using the two different conditions described below. The first crystals of the 3,6-diketocamphane monooxygenase oxygenating component grew from $0.2 \mathrm{M}$ sodium acetate and $15 \%$ PEG 8000 in about 1-2 weeks and were typically thin plate-shaped crystals that were $0.5 \times 0.3 \times 0.05 \mathrm{~mm}$ in dimensions (Fig. $2 a$ ). These were harvested into a mother liquor containing 20\% PEG 8000 and $0.5 M$ sodium acetate. Large crystals were difficult to reproduce and were unstable on exposure to $\mathrm{X}$-rays. This 
allowed only $20^{\circ}$ of data to be collected to $2.8 \AA$ resolution at room temperature at the synchrotron radiation source. It was found that the crystals belong to the orthorhombic space group $P 2_{1} 2_{1} 2_{1}$ with unit-cell dimensions $a=55.8, b=94.5$ and $c=163.7 \AA$. Assuming the subunit molecular weight to be $42 \mathrm{kDa}$, the crystal can contain two subunits per asymmetric unit with a solvent content of $52 \%$, or one subunit with a solvent content of $76 \%$ (Matthews, 1968). Provided the 3,6-diketocamphane monooxygenase molecule is still dimeric in the crystal, two subunits per asymmetric unit seems to be plausible, as there are no proper rotational axes in this crystal space group.

The crystals of the second form had a rod-shaped morphology and were much thicker (Fig. $2 b$ ). They grew from $50 \mathrm{~m} M$ PIPES, $\mathrm{pH}$ 6.5, and $50 \%$ ammonium sulfate over several months. These were harvested into a mother liquor containing $30 \%$ glycerol, $50 \mathrm{~m} M$ PIPES, $\mathrm{pH} 6.5$, and $55 \%$

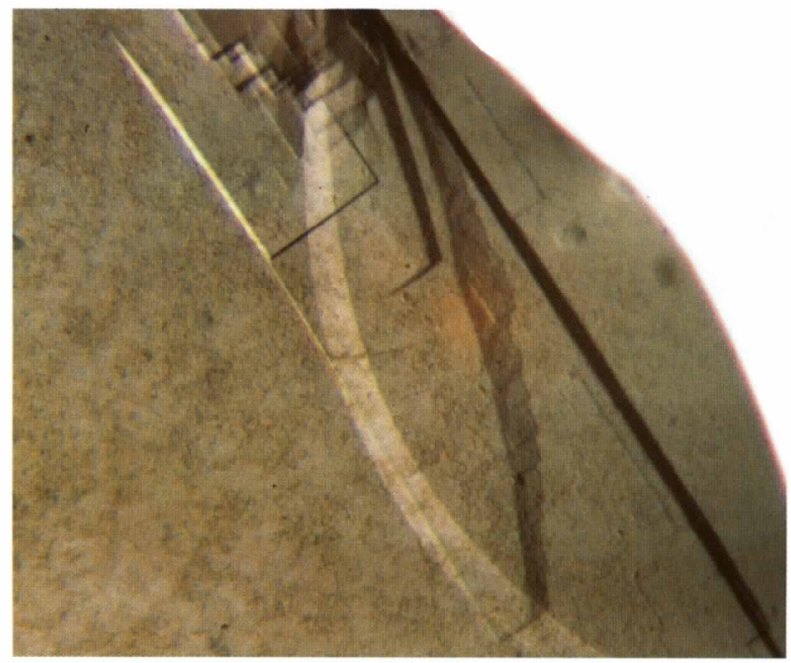

(a)

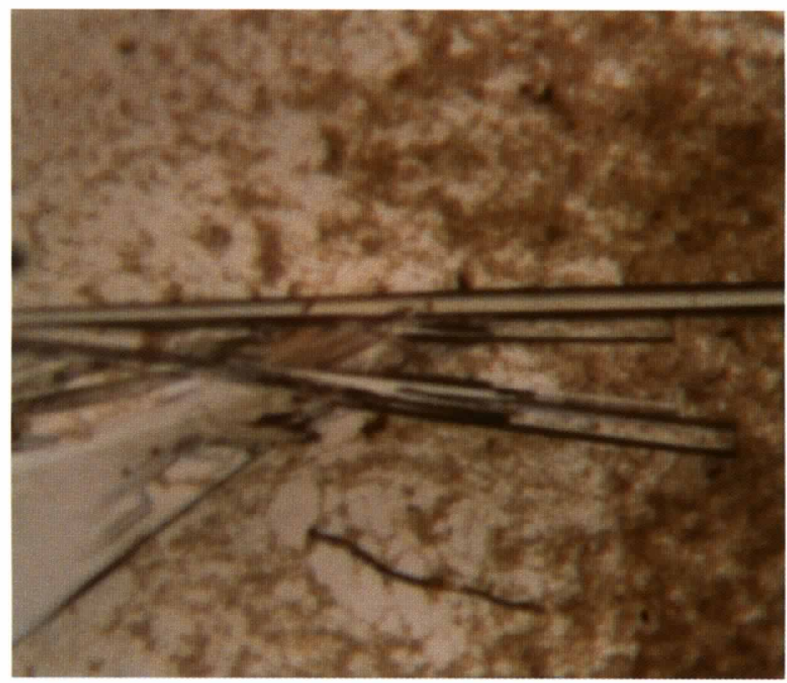

(b)

Fig. 2. Crystals grown from different conditions of 3,6-diketocamphane monooxygenase oxygenating subunits from $P$. putida. (a) Condition 1 , thin stacked crystalline plates. $(b)$ Condition 2 , thicker rod-shaped crystals.
Table 1. Statistics for the data collected from the ammonium sulfate grown crystals (condition 2)

Wavelength $(\AA)$

1.00

Resolution ( $\mathrm{A}$ )

$18-2.5$

Number of measured reflections

94431

Number of unique reflections

27982

Completeness (all data) (\%)

97.3

Completeness (highest-resolution shell) (\%) $\quad 96.9$

$I>2 \sigma(I)(\%)$

$R_{\text {sym }} \dagger$ (all data) (\%)

$R_{\text {sym }} \dagger$ (highest resolution shell) (\%)

80.6

7.8

$R_{\text {stand }}(I) \ddagger$ (all data) $(\%)$

$\dagger R_{\text {sym }}=\sum\left(\sum_{i}\left|I_{i}-\langle I\rangle\right|\right) / \sum\langle I\rangle$ where $\langle I\rangle$ is the mean of the intensity measurements, $I_{i}$, and the summation extends over all reflections. $\ddagger R_{\text {stand }}(I)=\langle\sigma(I)\rangle /\langle I\rangle$.

ammonium sulfate. These crystals diffracted to beyond $2 \AA$ resolution, allowing a complete data set to be collected to $2.5 \AA$ resolution at $100 \mathrm{~K}$. The space group was again identified as $P 2_{1} 2_{1} 2_{1}$, with unit-cell dimensions $a=54.6, b=93.2$ and $c=154.1 \AA$. The statistics for the $2.5 \AA$ data are given in Table 1 . The asymmetric unit could contain either two subunits with a calculated solvent content of $47 \%$, or one subunit with a solvent content of $74 \%$ (Matthews, 1968). Provided the molecule retains its dimeric state in the crystal, the asymmetric unit is unlikely to contain a single subunit as there are no proper rotational axes in $P 2_{1} 2_{1} 2_{1}$. One subunit per asymmetric unit cannot be ruled out completely, as the protein could crystallize as a monomer rather than in its dimeric form.

Self-rotation functions (Collaborative Computational Project, Number 4, 1994) calculated with a range of integration radii and with different resolution limits showed no particular features for a range of values for $\kappa$. This could favour one molecule per asymmetric unit, but even in the case of two molecules per asymmetric unit the self-rotation function could be obscured by the relatively strong anisotropy of the data the ratio of eigenvalues of the anisotropic distribution of the structure factors is $0.59: 0.50: 1.00$ as estimated by the program SFCHECK (A. Vagin, personal communication). Alternatively, the non-crystallographic molecular dyad could be almost parallel to one of the crystallographic axes and thus be shadowed by the latter in the self-rotation function. The native Patterson does not contain any significant features which could indicate pseudotranslation. Therefore, if there is a molecular dyad in these crystals it is unlikely that it is precisely parallel to one of the crystallographic twofold axes.

The observation that a similar crystal form can be grown from both PEG 8000 and ammonium sulfate will be useful when carrying out substrate soaks or co-crystallization experiments where the transfer of crystals from ammonium sulfate into polyethylene glycol may be necessary. A search for heavy-atom derivatives is currently in progress.

We would like to thank the BBSRC for support of an earmarked studentship (EJM), two postdoctoral fellowships (ES and MNI) and for an equipment grant (JAL).

\section{References}

Collaborative Computational Project, Number 4. (1994). Acta Cryst. D50, 760-763.

Conrad, H. E., Lieb, K. \& Gunsalus, I. C. (1965). J. Biol. Chem. 240 , 4029-4037. 
Gagnon, R., Grogan, G., Levitt, M., Roberts, S. M., Wan, P. W. H. \& Willetts, A. J. (1994). J. Chem. Soc. Perkin Trans. pp. 2537-2543.

Grogan. G. (1995). PhD thesis. University of Exeter, England.

Grogan, G., Roberts, S. M. \& Willetts, A. J. (1992). Biotech. Lett. 14, 1125-1130.

Grogan, G., Roberts, S. \& Willetts, A. J. (1993). J. Chem. Soc. Chem. Commun. pp. 699-701.

Grogan, G., Roberts. S., Wan. P. \& Willetts, A. J. (1993). Biotech. Lett. 15. 913-918.

Gunsalus, I. C. \& Marshall, V. P. (1971). Crit. Rev. Microbiol. 1, 1099 1119.
Jones, K. H., Smith, R. T. \& Trudgill, P. W. (1993). J. Gen. Microbiol. 139, 797-805.

LeGall, J., Bertland, A. U., Namtvedt, M. J. \& Conrad, H. E. (1963). Fed. Proc. Fed. Am. Soc. Exp. Biol. 22, 295.

McGhie, E. J. \& Littlechild, J. A. (1996). Biochem. Soc. Trans. 24. 29. Matthews, B. (1968). J. Mol. Biol. 33, 491-497.

Otwinowski, A. \& Minor, W. (1997). Methods Enzymol. 276, 307-326.

Taylor, D. G. \& Trudgill, P. W. (1986). J. Bacteriol. 165, 489-497.

Williams, R. (1991). PhD thesis. University of Abcrystwyth, Wales. 